\title{
The Constitution of Starch
}

$\mathrm{T}$ HE chemical structure of starch has not yet been fully elucidated. In recent years, evidence as to the size of its molecule has been derived from a study of the products obtained when trimethylstarch is broken down; and it is supposed that, like cellulose, starch consists of chains of glucopyranose residues, but united by $\alpha$-glucosidic instead of $\beta$-glucosidic links. Haworth has calculated that the molecule of starch consists of not more than 25-30 glucose units and that these units are associated into physical aggregates of much larger dimensions. On the other hand, Prof. Staudinger has long held the view that the physical properties of starch point to the existence of macro-molecules as distinct from molecular aggregates and in the May issue of the Berichte der deutschen chemischen Gesellschaft he and Herr Husemann adduce fresh evidence in support of this view from a study of the effect of chemical reactions upon the degree of polymerization of various preparations of starch from wheat.

The persistence of a particular degree of poly. merization, after the starch had been regenerated from an acetylated derivative, has been clearly demonstrated and is held to be conclusive proof of the existence of macro-molecules. The reason why such evidence has not hitherto been available is because these macro-molecules are far more sensitive than ordinary molecules to disruptive agencies and it has been shown that even traces of atmospheric oxygen in the solvent exert an enormous effect upon the degree of polymerization.

The starch was first freed from phosphoric acid and purified by repeated precipitation by methanol from solution in formamide. Osmotic pressure measurements of a solution of this in formamide indicated a molecular weight of 286,000 or a polymerization degree of 1770 . Another preparation with a polymerization degree of only 600 was obtained from it by rapid hydrolysis with normal hydrochloric acid. The two preparations were then acetylated, the former giving an insoluble, the latter a soluble, derivative. The acetylated compounds were then hydrolyzed by sodium methylate under very stringent conditions, when it was found that the polymerization of the regenerated starches had only been reduced to 1640 and 530 respectively. In view of the difficulty of eliminating the last traces of atmospheric oxygen during the alkaline hydrolysis, it is claimed that the degree of polymerization of the starch was materially unaltered by the process of acetylation. Viscosity measurements led to the same conclusion.

Starch appears to be not one compound but a kind of polymeric series. From the relation between degree of polymerization and specific viscosity the macromolecules of starch must be quite different in structure from the micelles of cellulose for the viscosity of the latter is 5-10 times as great as that of starch of the same degree of polymerization. Since, however, the viscosity of the solution may be taken as a measure of the length of the dissolved molecules, those of starch must be very much shorter and are therefore coiled. It is also suggested that the coils are branched and the ends of the short glucose chains are linked in glucosidic fashion with hydroxyl groups of other chains. This structure would not only account for a relatively high proportion of tetra. methyl glucose among the fission-products of trimethyl starch but also for the complete absence of aldehydic properties in starch itself.

\section{River Tees Survey}

T $\mathrm{HE}$ beauty and purity of our rivers is a national heritage, and the increasing attention that is being turned towards problems of pollution is therefore welcome. But before the causes and effects of pollution can be truly understood it is necessary to have, as a foundation, a knowledge of the natural, unpolluted state. One of the most important. British contributions in this respect is to be found in a recent publication of the Water Pollution Board of the Department of Scientific and Industrial Research*. This report is concerned with the non-tidal reaches of the River Tees and supplements the work on the tidal region previously published. The survey was undertaken by the Ministry of Agriculture and Fisheries, the research staff being under the direction of Dr. E. S. Russell. The report is drafted by Dr. R. W. Butcher, Dr. J. Longwell and Mr. F. T. K. Pentelow, who were botanist, chemist and zoologist, respectively, on the survey.

A comprehensive chemical and biological survey was made and many experiments performed in the laboratory on the effects of sewage pollution. It was found

- Department of Scientific and Industrial Research. Water Pollution Research Technical Paper No. 6. Survey of the River Tees. Part 3. The Non-Tidal Reaches-Chemical and Biological. By R. W. Butcher, J. Longwell, and F. T. K. Pentelow. (London: H.M. Stationery Office, 1937.) 128. 6 d. net. that the River Tees could conveniently be divided into two regions, namely, from the source at Cross Fell to the junction with the River Skerne at Croft Bridge, a river mileage of 55 miles, and from Croft Bridge to Yarm, a distance of 24 miles. Above the junction with the Skerne, the Tees waters are fairly soft, and slightly alkaline, except at periods of heavy flood. The flora and fauna in this region are uniform, taking into consideration differences to be expected from type of bottom and rate of flow. The only pollution comes from several small sewage works between Middleton-in-Teesdale and Croft, but the dilution by the river is sufficiently great to prevent harmful effects.

The River Skerne is, however, quite different ; its water is very hard and it is heavily polluted with sewage effluent from Darlington. The Skerne water on entering the River Tees produces a marked change in the chemical and biological characteristics of this lower reach. The hardness of the water is increased, as is also the amount of organic matter in solution and in suspension, with a resultant lowering of the oxygen content. The composition of the flora and fauna is different from that above Croft Bridge, but owing to the presence of nutritive substances from the sewage effluent the numbers of plants and animals are greater. By comparing the two regions 
of the Tees it was possible to discriminate certain organisms as useful indicators of pollution.

The work opens up a number of questions, not only of economic importance but also of direct scientific interest. One of the most noteworthy points disclosed is our complete lack of knowledge concerning the life-histories of so many of those insects which form the major constituents in the food of trout and other fish. It was found impossible to identify many of the larval stages as these have never been described. The necessity for a comprehensive survey of this subject is stressed.

\section{The Study}

$\mathrm{O}^{\mathrm{N}}$ three occasions recently the Indian journal Current Science has appeared as a special issue devoted to a particular topic. The third of these, dated March 1938, is devoted to genetics. It includes eight short reviews by acknowledged authorities, held together by an introduction by Dr. Eileen W. E. Macfarlane.

Dr. H. J. Muller writes on "The Present Status of the Mutation Theory", discussing the nature and the mode of action of the gene. The following section headings indicate the scope of his contribution : the gene as the material basis of mutation; the quantitative study of the nomal mutation frequency; thermal and chemical influences on the mutation process ; the production of mutations by irradiation; effects of mutations on the organism; changes in gene arrangement; and gene mutations as the primary steps of evolution.

Prof. $O$. Winge gives a very concise and clear review of the facts concerning the cytology of sex. He describes his own experiments on Lebistes in some detail in order to support his opinion that sex genes are present in all chromosomes and that there is always the possibility that the sex chromosome may become changed into an autosome and vice versa.

Prof. Kihara provides a short article on cytogenetics of species hybrids, whilst Dr. H. B. Frost, in an article on the genetics and cytology of citrus, furnishes a valuable example of the application of these disciplines to the study of a special group of economic value.

Special aspects of evolution are dealt with in the contributions by Prof. E. B. Babcock on phylogeny in the light of genetics and cytology and by Prof. A. F. Shull on adaptation in the light of genetics. The former stresses the importance of genetics, and particularly of comparative cytology, in discussions concerning phylogenetic relationships between groups of animals and plants, and illustrates his views with references to data from his and his co-workers' researches on the genus Crepis. Prof. Shull discusses the possible ways in which adaptation may have arisen through the interplay of mutation and selection, and suggests the lines which future work might profitably take when the problems of selection are being studied genetically.

Dr. C. B. Davenport in his "Genetics of Human Inter-racial Hybrids" stresses the importance of studies of this kind in regions where hybridization is just beginning, so that the first and second hybrid generations may be definitely known. He suggests that the regions where such studies might be profitably made are the Amoor River region in Siberia where the Siberians are coming into contact with the Japanese, in certain regions in Africa where the whites are meeting the practically full-blooded Negro stock, and in North America where the Eskimo and the white are now newly meeting.

The final article is by Dr. C. B. Bridges, who discusses in a most attractive way the future of genetics.

\section{of Genetics}

$\mathrm{He}$ is of opinion that the near future will see genetical studies extended to an ever-increasing number of animal and plant forms ; the intensive study of such forms as have so far failed to conform to established genetic principles, such studies leading to the consequent extension of those principles and to the invention of new hypotheses and the simplification of the old; the elaboration of new technical methods in genetic experimentation and in cytology; the employment of further physical or chemical and environmental agencies in the induction of cytogenetic novelty; the hybridization of genetics and cytology with other sciences such as chemistry, embryology, physiology ; and finally, the progressive clarification of man's philosophical outlook as to his origin, development and activities, with the rescue of still other departments of life from the deistic and vitalistic to the naturalistic and mechanistic realms.

Dr. Bridges recommends studies of bacteria and viruses and phages for an understanding of gene action and of the nature of sex, and points out that the gene now occupies for us the place held by the cell for a previous generation of biologists. The gene must be analysed in terms of its physical structure and chemical behaviour. For the moment we think of it as a crystalline body, probably of the fibre type, the autocatalytic growth of which is by surface condensation of constituent simpler materials from the surrounding medium, and its reproduction is pictured as a simple split of this fibrous crystal when its growth has exceeded the size limits proper to its internal bonding versus the disruption due to temperature and other environmental factors. The model of gene structure must allow not only of autocatalytic growth and self-reproduction, but also of compositional change and the subsequent perpetuation of that new structure. On the hypothesis that the fields of force on the surface of the gene control its crystalline growth, it is conceivable that rare acceptance of a misfit building block would alter the surface material. The interpretation of 'position effects' will probably follow the idea that the action of the gene is limited by materials which diffuse into it. The induction of changes in the gene and in the chromosome by the use of radiations and of chemical agents is now only just begun. By their extended use, problems of the size, number, structure, mutability and action of the gene have become soluble. The cytologists may be expected to continue and elaborate their studies of the salivary gland chromosomes, and will proceed intensively to study the phenomena involved in the synapsis, crossing-over and distribution of chromosomes to the gametes.

Reading these articles, one cannot but be impressed by the extraordinary activity that is everywhere present in the field of genetics, by the luxuriance of its growth, and especially by its promise of great adventure. 